\title{
Treatment patterns of childhood diarrhoea in rural Uganda: a cross-sectional survey
}

\author{
Jenny Löfgren ${ }^{1}$, Wenjing Tao ${ }^{1}$, Elin Larsson ${ }^{1}$, Francis Kyakulaga ${ }^{2}$ and Birger C Forsberg ${ }^{1 *}$
}

\begin{abstract}
Background: Diarrhoea is the second leading cause of death in children under five accounting for 1.8 million deaths yearly. Despite global efforts to reduce diarrhoea mortality through promotion of proper case management, there is still room for ample improvement. In order to seek options for such improvements this study explored the knowledge and practices of diarrhoea case management among health care providers at health centres and drug shops in Uganda.

Methods: Records were reviewed for case management and structured interviews concerning knowledge and practices were conducted with the staff at all health centres and at all identified drug shops in the rural district of Namutumba, Uganda.

Results: There was a significant gap between knowledge and documented practices among staff. Antibiotics, antimalarials and antipyretics were prescribed or recommended as frequently as Oral Rehydration Solution (ORS). In almost a third of the health facilities, ORS was out of stock. $81 \%$ of staff in health centres and $87 \%$ of staff in drug shops stated that they prescribed antibiotics for common diarrhoea. Zinc was not prescribed or recommended in any case.

Conclusions: The findings indicate that many children presenting with diarrhoea are inadequately treated. As a result they may not get the rehydration they need and are at risk of potential side effects from unjustified usage of antibiotics. Practices must be improved at health centres and drug shops in order to reduce childhood mortality due to diarrhoeal diseases.
\end{abstract}

Keywords: Diarrhoea, Diarrhoea case management, Diarrhoea control, Oral rehydration, Child health, Uganda

\section{Background}

Diarrhoea is the second leading cause of under five mortality globally and it accounts for 1.8 million deaths annually [1]. The majority of these deaths occur in south Asia and Africa [2]. According to Bhutta et al., childhood mortality has fallen by $28 \%$ since 1990 in 68 prioritized countries. However, efforts need to increase substantially to achieve Millennium Development Goal 4 (MDG4) of reducing childhood deaths [3].

In order to reduce mortality and morbidity due to childhood diarrhoea, the "Programme for Control of Diarrhoeal Diseases" (CDD) was initiated by WHO at the beginning of the 1980s [4]. Diarrhoea caused an estimated 4.6 million deaths in children under five at that

\footnotetext{
* Correspondence: Birger.Forsberg@ki.se

'Division of Global Health, Department of Public Health Sciences, Karolinska Institutet, Nobels väg 9, 171 77, Stockholm, Sweden

Full list of author information is available at the end of the article
}

time [5]. The major cause of death due to diarrhoeal diseases is dehydration. The cornerstone in diarrhoea case management is to prevent or treat dehydration [6]. Oral Rehydration Therapy (ORT) was therefore chosen as the primary intervention in the CDD programme. Subsequently, usage of ORT increased which contributed to reductions in diarrhoea mortality in low- and middleincome countries (LMIC) [7,8]. Even so, the usage of ORT is still unsatisfactory in many LMIC [9].

In 2004, an additional therapy, zinc, was added to the recommended treatment of diarrhoea in children. Zinc has been found to reduce the duration and severity of the diarrhoea episode and lower the incidence of diarrhoea during the months following the episode [10-12]. Later, zinc has also been shown to reduce mortality from diarrhea [13].

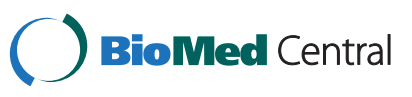


Advice on health issues in low-income countries is often sought from private practitioners and drug vendors $[14,15]$. In many cases, an untrained drug vendor becomes an important source of information and treatment during childhood diarrhoea [16].

This study investigated knowledge and practices among staff at health centres (HC) and drug shops (DS) in a rural setting in Uganda in order to explore the scope for improvement of diarrhoea case management.

\section{Methods}

\section{Study setting}

The study was carried out in Namutumba district, located about $125 \mathrm{~km}$ north east of Kampala, the capital of Uganda. This rural district had a population close to 200000 at the time of the study. There were 33 registered $\mathrm{HC}$ in the district (21 governmental, $12 \mathrm{NGO}$ run). Health centres in Namutumba district range from level two to level four. (Health facilities in Uganda are divided into seven levels where level 1 is the village health team, 2-4 HC, 5-6 hospitals and 7 the national referral hospital in Kampala.) There were no pharmacies in the district while 10 drug shops were registered with the district headquarters.

\section{Study participants and data collection}

All registered health centres in Namutumba district were included in the study. In each facility a structured interview was carried out by the lead researcher assisted by an interpreter. In the lower level health centres there was typically only one staff available. When more than one staff was present the best educated person was interviewed. All staff approached consented to participate. In the interviews respondents' knowledge on diarrhoea and diarrhoea management as well as their stated practices were assessed. The questionnaire was constructed with a combination of closed and open ended questions.

A review of the outpatient register was also done by the lead researcher. Information about diagnosis and recommended treatment for all cases of diarrhoea in children under the age of five during the past two months were recorded. A facility inventory was made in all facilities to check for availability of ORS, drugs and clinical guidelines.

Interviews, record reviews and inventories were conducted in all but two $\mathrm{HC}$ that were closed at the time of visit.

Drug shops were identified on arrival in the 24 villages where the $\mathrm{HC}$ were located. All drug shops that could be identified were visited by the research team. In most ( $n=46$ ) of the identified DS, a structured interview was performed by the lead researcher with the assistance of an interpreter. In most cases there was only one person attending the DS. The design of the questionnaire was similar to the one used in the HC. In four cases, interviews could not be undertaken because the staff either declined to participate or was absent.

\section{Data analysis}

Data were entered in MS Excel 2011, cleaned for any inconsistencies and analysed for standard distribution measurements. Student's two-tailed t-tests were performed to determine p-values for differences between health centres and drug shops. P-value $<0.05$ was considered significant. Calculations of confidence intervals assumed normal distribution of proportions.

\section{Ethics}

The study was approved by the Ethics Committee at Uganda Christian University, Mukono, Uganda. All participants gave informed consent and signed a consent form prior to participation in the study.

\section{Results}

77\% (24) of the $\mathrm{HC}$ visited were level two facilities, $19 \%$ (6) level three and 3\% (1) level four. The respondents in the $\mathrm{HC}$ were nursing assistants (65\%), nurses/midwives (26\%) or clinical officers (15\%). All respondents in both $\mathrm{HC}$ and DS had 3-6 years of secondary schooling and a majority of the respondents at the $\mathrm{HC}$ had attended a nursing school. The respondents at the DS were nursing assistants $(82 \%)$ or nurses/midwives (15\%). One person was a veterinary assistant $(2 \%)$.

\section{Knowledge about causes, symptoms and danger signs of diarrhoea in children}

The respondents were asked to mention causes, symptoms and danger signs of childhood diarrhoea. The causes have been classified into four categories: feeding and drinking, hygiene, microbes, and concomitant diseases (table 1). The symptoms and danger signs are divided into four categories: dehydration, gastrointestinal, general condition and other. The three most commonly stated symptoms in the respective category are listed in table 2. (Respondents gave multiple answers.)

There was a statistically significant difference $(\mathrm{P}<0.05)$ between the respondents at the $\mathrm{HC}$ and $\mathrm{DS}$ regarding knowledge about causes $(\mathrm{p}=0.03)$, but not about symptoms $(p=0.12)$ and danger signs $(p=0.33)$. The respondents in the HC more frequently (52\%) mentioned microbes as pathogens in diarrhoea than those in the DS (17\%). Staff in the HC was more familiar with signs of dehydration both as symptom ( $68 \%$ vs. $30 \%)$ and danger sign (77\% vs. $43 \%$ ) than the staff in DS. At the HC, the frequency of correct and detailed answers increased with the level of training. For example, 100\% of the clinical officers and nurses mentioned dehydration symptoms while only 
Table 1 Causes of diarrhoea as stated by respondents at health centres and drug shops

\begin{tabular}{lll}
\hline & $\begin{array}{l}\text { Health centre } \\
(\mathbf{n}=\mathbf{3 1})\end{array}$ & $\begin{array}{l}\text { Drug shop } \\
(\mathbf{n}=\mathbf{4 6 )}\end{array}$ \\
\hline Feeding and drinking & $\mathbf{2 4}(\mathbf{7 7 \% )}$ & $\mathbf{3 5}(\mathbf{7 6} \%)$ \\
Contaminated food and feeding practices & $20(65 \%)$ & $31(67 \%)$ \\
Contaminated water & $13(42 \%)$ & $26(57 \%)$ \\
Malnutrition & $8(26 \%)$ & $2(4 \%)$ \\
Weaning/mixing food & $5(16 \%)$ & $2(4 \%)$ \\
Hygiene, sanitation and environment & $\mathbf{1 9}(\mathbf{6 1 \% )}$ & $\mathbf{2 4}(\mathbf{5 2} \%)$ \\
Microbes & $16(52 \%)$ & $8(17 \%)$ \\
Bacteria & $6(19 \%)$ & $2(9 \%)$ \\
Worms & $15(48 \%)$ & $5(11 \%)$ \\
Other & $3(16 \%)$ & - \\
Other diseases & $\mathbf{2 0 ( 6 5 \% )}$ & $\mathbf{2 5 ( 5 4 \% )}$ \\
Malaria & $20(65 \%)$ & $25(54 \%)$ \\
Measles & $7(23 \%)$ & $10(22 \%)$ \\
Other & $4(13 \%)$ & $3(7 \%)$ \\
Other causes & $\mathbf{5 ( 1 6 \% )}$ & $\mathbf{2 ( 7 \% )}$ \\
\hline
\end{tabular}

$75 \%$ of the nursing assistants did so. All clinical officers mentioned several microbes as causing diarrhea compared to $75 \%$ and $35 \%$ of the nurses and nursing assistants respectively.

\section{Practices in childhood diarrhoea case management}

A majority of the respondents at the $\mathrm{HC}(87 \%)$ and the DS (67\%) mentioned ORS as the primary treatment in childhood diarrhoea, followed by antibiotics (13\% at HC, $26 \%$ at DS). The most desired stated outcome from treating diarrhoea was cure or reduction of the frequency of loose stools ( $42 \%$ in HC, $70 \%$ in DS). The second most wanted outcome was rehydration (39\% in the $\mathrm{HC}, 20 \%$ in the DS). In the $\mathrm{HC}$, better educated staff was more prone to mention rehydration as the desired outcome than less educated staff.

When asked about actual practices, $87 \%(\mathrm{HC})$ and 70\% (DS) mentioned that they gave ORS. $81 \%(\mathrm{HC})$ and $87 \%$ (DS) stated that they prescribed antibiotics. Antimotility drugs were never mentioned in the $\mathrm{HC}$, but by $9 \%$ of the respondents in DS. Zinc was never mentioned as a recommended treatment, neither in $\mathrm{HC}$ nor in DS, but $55 \%$ at the $\mathrm{HC}$ and $50 \%$ at the DS had heard about the zinc preparation promoted in Uganda. At the time of the study, zinc was not included in the clinical guidelines from the Ministry of Health $(\mathrm{MoH})$ and it was not provided to the health centres. Differences in practices between $\mathrm{HC}$ and DS were not statistically significant.

The facility inventory showed that $77 \%$ of the $\mathrm{HC}$ and $63 \%$ of the DS had ORS in stock. The stated reason for stock outs at the $\mathrm{HC}$ was delayed delivery from central medicine depots, and in the DS that the owner had not ordered ORS. $\mathrm{MOH}$ clinical guidelines were available in $68 \%$ of the $\mathrm{HC}$ and in $4 \%$ of the DS.

\section{Record review}

In the record review, 523 cases of childhood diarrhoea were identified. Most cases were diagnosed and treated for concomitant conditions such as malaria (83\%, 95\% Confidence Interval (CI) 80-86) and respiratory tract infection $(16 \%, 95 \%$ CI 13-19). Dysentery was uncommon (2\%, 95\% CI 1-3). The most commonly recommended treatments were antimalarials $(82 \%, 95 \%$ CI $79-85)$ and

Table 2 Symptoms and danger signs of diarrhoea as stated by the respondents at health centres and drug shops (\%)

\begin{tabular}{|c|c|c|c|c|}
\hline & \multicolumn{2}{|c|}{ Regular symptoms } & \multicolumn{2}{|c|}{ Danger signs } \\
\hline & Health centre $(n=31)$ & Drug shop $(n=46)$ & Health centre $(n=31)$ & Drug shop $(n=46)$ \\
\hline Dehydration symptoms & 68 & 30 & 77 & 43 \\
\hline Sunken eyes & 26 & 15 & 48 & 35 \\
\hline Decreased skin turgor & 52 & 13 & 26 & 26 \\
\hline Thirst & 26 & 4 & 13 & 2 \\
\hline Gastrointestinal symptoms & 48 & 33 & 16 & 24 \\
\hline Loose and frequent stools & 35 & 7 & 10 & 4 \\
\hline Abdominal discomfort and pain & 13 & 13 & - & 2 \\
\hline Vomiting & 10 & 7 & 6 & 4 \\
\hline General condition & 61 & 70 & 45 & 41 \\
\hline Weakness and malaise & 32 & 41 & 26 & 22 \\
\hline Loss of apetite & 19 & 33 & 10 & 9 \\
\hline Altered body temperature & 16 & 7 & 3 & 15 \\
\hline Other symptoms & 19 & 20 & 13 & 11 \\
\hline Do not know & - & 7 & - & - \\
\hline
\end{tabular}


analgetics $(80 \%, 95 \%$ CI $77-83)$ followed by rehydration therapy $(78 \%, 95 \%$ CI $74-82)$, antibiotics $(76 \%, 95 \%$ CI 72-80), deworming medicines (32\%, 95\% CI 29-35), vitamins and trace elements $(16 \%, 95 \%$ CI 13-19) and other (4\%, 95\% CI 2-6).

\section{Discussion}

Diarrhoeal diseases is a major target in the global efforts to increase survival and reduce the disease burden in children [2]. Prevention is of primary importance in these efforts but adequate management of cases is essential to reduce mortality, in particular the administration of Oral Rehydration Solutions (ORS) to treat dehydration [3]. The findings in this study highlight areas for improvement in diarrhoea case management.

Respondents' knowledge about symptoms and danger signs of dehydration showed positive results but also that there was room for improvement. Such knowledge is essential as most deaths from diarrhoea are caused by dehydration. Staff in HC generally scored better than those in DS. Further training of staff on diarrhoea, its symptoms and potential consequences is called for. In particular, clinic based training with hands-on experience from treating cases should be considered as it has proven to be particularly effective [4].

Knowledge on treatment with ORS was generally good. ORS was the stated first hand treatment choice in $87 \%$ of the interviews in the $\mathrm{HC}$ and in $67 \%$ of the DS. Equally many (87\% respectively $70 \%$ ) claimed that they recommend ORS in real practice. In the record review $78 \%$ of the cases had been given rehydration therapy. Still, it was only the third most commonly recommended medicine in childhood diarrhoea. In one third of the facilities ORS was out of stock.

Overuse of inappropriate medication during childhood diarrhoea is common $[15,16]$. Antibiotics are extensively used in diarrhoea case management [17-19], even though they are only recommended in few cases of diarrhoea. Anti-diarrhoeal medicines are not recommended at all in children [20-22].

Antibiotics are often attained from other sources than from trained medical personnel [23]. In the present study over $80 \%$ of the respondents stated they recommend antibiotics. Still, antibiotics are only indicated in dysentery, cholera and for certain cases of persistent diarrhea $[2,24]$. Overuse cause potentially harmful side effects and contributes to bacterial resistance development [25]. In the record review, dysentery was a rare diagnosis $(2 \%)$ and it cannot motivate that $76 \%$ of the cases were recommended antibiotics.

Despite the high use of antibiotics, microbes were not mentioned equally frequent as pathogens in diarrhoea (52\% in $\mathrm{HC}$ and $17 \%$ in DS). Worms and bacteria were the most well-known microbes while viral pathogens, that often cause childhood diarrhea [26], were never mentioned. Improved knowledge about diarrhoea etiology and when to treat with antibiotics, could possibly decrease the antibiotic usage.

Antidiarrhoeals were never recommended in the $\mathrm{HC}$ and sold in only $9 \%$ of the DS, corresponding to a much lower use rate than that of previous studies [21].

Previous studies have suggested that caretakers may prefer a combination of ORS and other medicines to single therapy with ORS. Zinc has shown to increase ORS usage [27] and reduce the use of antibiotics and antidiarrhoeals [28]. In our study zinc was never used but half of the respondents had heard about the medicine. A recent study from India showed that, even when available, zinc is rarely used [29]. Zinc was introduced as standard treatment in childhood diarrhoea through the WHO/ UNICEF joint statement on the clinical management of acute diarrhoea in 2004 [10]. However, it is often unavailable in most countries due to difficulties in including it in national policy plans or due to lack of funding [30]. This was also the case in Uganda at the time of the study. Efforts need to be made to increase the availability of zinc so that children with diarrhoea can benefit from the therapy.

Correct management of diseases relies on correct knowledge on causes, symptoms and therapies. The frequency of correct answers in the interviews increased with the level of education, but care was often provided by the least educated personnel. Adequate and continuous training will most likely contribute to improved diarrhoea case management. Training within the IMCI strategy has previously shown to significantly improve the quality of care for children under five [31].

Drug shops are often the first line of health care in low-income settings like Namutumba district so it is crucial to also involve drug shop attendants in training. Registration and monitoring of DS is needed to reach this group of health care providers with information and training opportunities.

We agree with other researchers that "training is not enough" [31] and other measures must be taken parallel to knowledge transfer to achieve desired changes in behaviour. Still knowledge among providers is a necessary pre-requisite for large-scale and sustainable improvements in case management.

Most children in the record review were recommended treatment for concomitant diseases. Possibly the integrated child case management has contributed to this diagnostic overlap as diagnoses in this setting generally are based on history and clinical examination. In reality, cross diagnosing decrease the risk of missing a case of any of the three potentially life-threatening childhood diseases in the study setting (malaria, pneumonia and diarrhoea). The issue of overlapping symptoms in 
child illnesses in Uganda has been extensively studied and discussed for pneumonia and malaria [32]. Overlap issues in diarrhoea have been much less studied and should be a focus in future research.

\section{Methodological considerations}

The results from this provider survey are higher for ORS prescription than for ORS use as documented in community household surveys from the area. There are several reasons for this discrepancy. One is that some community members do not seek care from the providers investigated and their case management is likely to differ from those who seek a provider's advice. Another is that the ORS prescribed may not be bought or little, if at all, used. Hence, we cannot draw conclusions on community practices from a survey of providers.

The record reviews at the $\mathrm{HC}$ registered the recommended medicines. It was not specified whether the medicines were given at the facility or had to be purchased elsewhere.

Most drug shops in the district were visited but since there was no official registration of DS, some DS may have been missed in the sample. However, it was clear from interviews that the large majority of drug shops were identified and included in the study.

The study was carried out in a rural district in Uganda which limits its generalisability. However, as documented its findings are in line with findings from other places.

The principal investigator of the study was performing the interviews together with an interpreter. This arrangement was selected to improve quality control. However, it may have increased the risk of over-reporting good practices. Generally, self-reported practices have lower validity than other more objective measurements. In this study, record reviews served as such a measurement. It is a limitation of the study that no such records were available in drug shops.

\section{Conclusions}

The findings show that ORS use is well established but antibiotics continue to be overprescribed and the zinc usage is not taking off as it should. A number of interventions are needed to improve the service delivery. Continuous training for health care providers in both $\mathrm{HC}$ and DS is a necessary, though not always sufficient, pre-condition for improved practices. Particular efforts should be made to increase ORS usage, to introduce zinc in routine practice and to decrease the significant overuse of antibiotics. Procurement and logistics around delivery of medicines need to be improved so that ORS and zinc are always in stock in HC and DS. The study underlines the need for intensified operational research on implementation of recommended diarrhoea case management as proposed by an international study group in 2009 [33]. Such research is even more called for after the recent appeal by President Museveni and former US President Bill Clinton to accelerate the fight against diarrhoea in Uganda [34].

\section{Competing interests}

The authors declare that they have no competing interests.

\section{Authors' contributions}

$J L$ designed the study along with co-authors, performed the data collection, analysed data and wrote the manuscript. WT participated in the data collection and study design. EL contributed to the study design and data analysis. FK supervised the data collection and contributed to the study design. BF initiated the study and supervised all parts of it, including study design, data analysis and manuscript editing. All authors commented on the manuscript. All authors read and approved the final manuscript.

\section{Acknowledgement}

The authors would like to thank Professor Max Petzold, Akademistatistik, The Sahlgrenska Academy, University of Gothenburg, for assistance with the statistical analysis.

\section{Author details}

'Division of Global Health, Department of Public Health Sciences, Karolinska Institutet, Nobels väg 9, 171 77, Stockholm, Sweden. ${ }^{2}$ Department of Health Sciences, Uganda Christian University, Mukono, Uganda.

Received: 14 December 2011 Accepted: 27 August 2012

Published: 25 September 2012

\section{References}

1. World Health Organization: The global burden of disease, update 2004. Geneva: World Health Organization; 2008.

2. The United Nations Children's Fund (UNICEF)/World Health Organization (WHO). Diarrhoea: Why children are still dying and what can be done. Geneva: World Health Organization; 2009.

3. Bhutta ZA, Chopra M, Axelson H, Berman P, Boerma T, Bryce J, et al: Countdown to 2015 decade report (2000-10): taking stock of maternal, newborn, and child survival. Lancet 2010, 375:2032-44.

4. Merson MH: The WHO Diarrhoeal Diseases Control Program: the practical application of oral rehydration therapy, Proceedings of the International Conference on Oral Rehydration Therapy - Washington. USAID; 1983:23-28.

5. Snyder JD, Merson MH: The magnitude of the global problem of acute diarrhoeal disease: a review of active surveillance data. Bull World Health Organ 1982, 60(4):605-13.

6. Richards L, Claeson M, Pierce NF: Management of acute diarrhoea in children: lessons learned. Pediatr Infect Dis J 1993, 12:5-9.

7. Victora CG, Olinto MTA, Barros FC, Nobre L: Falling diarrhoea mortality in Northeastern Brazil: did ORT play a role? Health Policy Plan 1996, 11 (2):132-141.

8. Victora CG, Bryce J, Fontaine O, Monasch R: Reducing deaths from diarrhoea through oral rehydration therapy. Bull World Health Organ 2000, 78:1246-1255.

9. Forsberg BC, Petzold MG, Tomson G, Allebeck P: Diarrhoea case management in low- and middle-income countries - an unfinished agenda. Bull World Health Organ 2007, 85:42-48.

10. WHO/UNICEF: Joint statement on the clinical management of acute diarrhoea. Geneva: World Health Organization; 2004.

11. Bhutta ZA, Bird SM, Black RE, Brown KH, Gardner JM, Hidayat A, et al: Therapeutic effects of oral zinc in acute and persistent diarrhoea in children in developing countries: pooled analysis of randomized controlled trials. Am J Clin Nutr 2000, 72:1516-22.

12. Fischer Walker CL, Black RE: Zinc for the treatment of diarrhoea: effect on diarrohea morbidity, mortality and incidence of future episodes. Int $J$ Epidemiol 2010, 39:i63-i69.

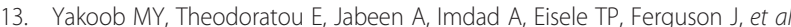
Preventive zinc supplementation in developing countries: impact on mortality and morbidity due to diarrhea, pneumonia and malaria. BMC Publ Health 2011, 11(Suppl 3):S23. 
14. Larson CP, Rani Saha U, Islam R, Roy N: Childhood diarrhoea management practices in Bangladesh: private sector dominance and continued inequities in care. Int J Epidemiol 2006, 35(6):1430-9.

15. Ellis AA, Winch P, Daou Z, Gilroy KE, Swedberg E: Home management of childhood diarrhoea in southern Mali - Implications for the introduction of zinc treatment. Soc Sci Med 2007, 64:701-12.

16. Ross-Degnan D, Soumerai SB, Goel PK, Bates J, Makhulo J, Dondi N, et al: The impact of face-to-face educational outreach on diarrhoea treatment in pharmacies. Health Policy Plan 1996, 11:308-18.

17. Raghu MB, Balasubramanian S, Balasubramanian G, Ramnath A, Indumathy: Drug therapy of acute diarrhoea: in children- actual practice and recommendations. Indian J Pediatr 1995, 62:433-437.

18. Mittal SK, Mathew JL: Regulating the use of drugs in diarrhoea. J Pediatr Gastroenterol Nutr 2001, 33:26-30.

19. Tomson G, Sterky G: Self-prescribing by way of pharmacies in three Asian developing countries. Lancet 1986, 2:620-2.

20. Haak H, Claeson M: Regulatory actions to enhance appropriate drug use: the case of antidiarrhoeal medicines. Soc Sci Med 1996, 42:1011-9.

21. WHO: The rational use of medicines in the management of acute diarrhoea in children. Geneva: World Health Organization; 1990.

22. Harris $\mathrm{S}$, Black R: How useful are pharmaceuticals in managing diarrhoeal diseases in developing countries? Health Policy Plan 1991, 6(2):141-147.

23. Winch P, FitzGerald MF: Formative research in preparation for promotion of zinc treatment for childhood diarrhoea: Cross-country comparison of diarrhoea treatment practices and implications for programs, Background document prepared for the meeting "Planning for Implementation of Zinc for Treatment of Diarrhoea. Baltimore, Maryland: Johns Hopkins Bloomberg School of Public Health; 2004:22-23.

24. Ahs J, Tao W, Löfgren J, Forsberg BC: Diarrhoeal diseases in low- and middle income countries: incidence, prevention and management. Open Infect Diseases Journal 2010, 4:113-124.

25. Okeke IN, Laxmanarayan R, Bhutta ZA, Duse AG, Jenkins $P$, O'Brien TF, et al: Antimicrobial resistance in developing countries. Part 1: recent trends and current status. Lancet Infect Dis 2005, 5:481-493.

26. Albert MJ, Faruque ASG, Faruque SM, Sack RB, Mahalanabis D: Case-control study of enteropathogens associated with childhood diarrhoea in Dhaka, Bangladesh. J Clin Microbiol 1999, 11:3458-3464.

27. Baqui AH, Black RE, El Arifeen S, Yunus M, Zaman K, Begum N, et al: Zinc therapy for diarrhoea increased the use of oral rehydration therapy and reduced the use of antibiotics in Bangladeshi children. $J$ Health Popul Nutr 2004, 22:440-2

28. Awasthi S: INCLEN Childnet Zinc Effectiveness for Diarrhoea (IC-ZED) group. Zinc supplementation in acute diarrhoea is acceptable, does not interfere with oral rehydration and reduces the use of other medications: a randomized trial in five countries. J Pediatr Gastroenterol Nutr 2006, 42:300-5.

29. Pathak D, Pathak A, Marrone G, Divan V, Stålsby Lundborg C: Adherence to treatment guidelines for acute diarrhoea in children up to 12 years in Ujjain, India - a crossectional prescription analysis. BMC Infect Dis 2011, 11 (32). [doi:10.1186/1471-2334-11-32].

30. Fischer Walker CL, Fontaine O, Young MW, Black RE: Zinc and low osmolarity oral rehydration salts for diarrhoea: a renewed call to action. Bull World Health Organ 2009, 87:780-786.

31. Pariyo GW, Gouws E, Bryce J, Burnham G: The Uganda IMCl impact study team. Improving facility-based care for sick children in Uganda: training is not enough. Oxford: Oxford university press; 2005.

32. Källander $\mathrm{K}$, Hildenwall $H$, Waiswa $\mathrm{P}$, et al: Delayed care seeking for fatal pneumonia in children aged under five years in Uganda: a case-series study. Bull World Health Organ 2008, 86(5):332-8.

33. Fontaine O, Kosek M, Bhatnagar S, Boschi-Pinto C, Chan KY, Duggan C, et al: Setting research priorities to reduce global mortality from childhood diarrhoea by 2015. PLoS Med 2009, 6(3):e1000041. [doi:10.1371/journal. pmed.1000041].

34. Clinton arrives to fight diarrhea in Uganda. Kampala: Daily Monitor; 2012.

doi:10.1186/1472-698X-12-19

Cite this article as: Löfgren et al:: Treatment patterns of childhood diarrhoea in rural Uganda: a cross-sectional survey. BMC International Health and Human Rights 2012 12:19.

\section{Submit your next manuscript to BioMed Central and take full advantage of:}

- Convenient online submission

- Thorough peer review

- No space constraints or color figure charges

- Immediate publication on acceptance

- Inclusion in PubMed, CAS, Scopus and Google Scholar

- Research which is freely available for redistribution 